\title{
INDICAÇÕES E USO DA TÉCNICA "SONDA-DEDO"
}

\section{Indications and use of "finger feeding"}

\author{
Cristina Ide Fujinaga (1), Ana Paula Duca (2), \\ Raquel Aparecida Cardozo de Lima Petroni ${ }^{(3)}$, Claudia Helena Rosa ${ }^{(3)}$
}

\begin{abstract}
RESUMO
A recomendação da Organização Mundial da Saúde é que todo recém nascido deva ser alimentado exclusivamente no seio materno até o sexto mês e, de forma complementar, até o segundo ano de vida. Assim, algumas técnicas são realizadas para facilitar a alimentação ao seio, dentre elas o uso do copo e, recentemente, a utilização da técnica "sonda-dedo". Tal prática é bastante controversa e há escassez de estudos na literatura sobre a descrição da técnica, sua indicação e uso. O objetivo do presente trabalho é relatar a experiência clínica para indicação e uso da técnica "sonda-dedo". A técnica "sonda-dedo" consiste no oferecimento do leite, de preferência humano, utilizando sonda gástrica conectada a uma seringa com êmbolo e fixada em dedo mínimo enluvado com fita adesiva. A sonda é posicionada na cavidade oral do recém nascido e deve servir como uma técnica de auxílio para adequação do padrão de sucção. Desta forma, sugere-se que sua indicação deve ser apenas nos casos em que seja caracterizada uma disfunção oral, seja em recém nascidos a termo ou prétermo. Diante da avaliação específica, realizada pelo fonoaudiólogo, indica-se a técnica "sonda-dedo" com objetivo de adequar as alterações obtidas na avaliação da sucção não nutritiva ou em seio materno. Acredita-se que, para que a técnica "sonda-dedo" seja indicada como complemento do aleitamento materno, devam ser realizados novos estudos para esclarecer quais as repercussões da técnica "sonda-dedo" na prevalência do aleitamento materno e no desenvolvimento motor oral de recém nascidos.
\end{abstract}

DESCRITORES: Recém Nascido; Alimentação; Aleitamento Materno

\section{INTRODUÇÃO}

A recomendação da Organização Mundial da Saúde é que todo recém nascido deva ser alimentado exclusivamente no seio materno até o sexto mês e, de forma complementar, até o segundo ano de vida. Várias são as vantagens do aleitamento materno, tanto para recém-nascidos a termo quanto pré-termo ${ }^{1}$. Para atender as recomendações de organizações nacionais e internacionais de proteção, apoio e incentivo ao aleitamento materno,

(1) Fonoaudióloga; Professor Adjunto B da Universidade Estadual do Centro-Oeste do Paraná/Brasil; Pós-doutor em Ciências/CNPq, pela de Escola de Enfermagem de Ribeirão Preto-USP,Brasil.

(2) Fonoaudióloga da UTI Neonatal do Centro Hospitalar Unimed, Joinville, Santa Catarina, Brasil; Mestre em Clinica Médica da Faculdade de Medicina de Ribeirão Preto-USP.

(3) Fonoaudióloga da UTI Neonatal do Hospital de Clínicas da Faculdade de Medicina de Ribeirão Preto da Universidade de São Paulo, Ribeirão Preto, São Paulo, Brasil.

Conflito de interesses: inexistente especialmente em instituições que possuem o título de Hospital Amigo da Criança, busca-se métodos alternativos à sucção a mamadeira, uma vez que essa é considerada prejudicial ao aleitamento materno por causar confusão de bicos². Assim, várias técnicas são realizadas para facilitar a alimentação ao seio, dentre elas o uso do copo, relactação e translactação ${ }^{3}$. Recentemente a utilização da técnica "sonda-dedo" também surge como uma alternativa na transição alimentar ${ }^{4}$. Tal prática é bastante controversa e há escassez de estudos na literatura sobre a descrição da técnica, sua indicação e uso. O objetivo do presente trabalho é relatar a experiência clínica para indicação e uso da técnica "sonda-dedo".

\section{MÉTODO}

Trata-se de um estudo descritivo. O texto de opinião é baseado no relato da experiência nos serviços prestados pelos fonoaudiólogos da Santa 
Casa de Irati-PR/Universidade Estadual do CentroOeste do Paraná, Centro Hospitalar UNIMED de Joinvile Santa Catarina e Hospital de Clínicas da Faculdade de Medicina de Ribeirão Preto da Universidade de São Paulo de Ribeirão Preto-SP. A literatura a respeito da indicação e uso da técnica "sonda-dedo" é extremamente escassa, apesar de o tema ser relevante e da prática dessa técnica ser comumente utilizada em diversos serviços, muitas vezes sem critérios objetivos e sistematizados. Cabe ressaltar que não se pretendeu a realização de estudo envolvendo sujeitos para comparação da técnica "sonda-dedo" com demais métodos alternativos de alimentação infantil, o qual deva ser realizado posteriormente.

As experiências das autoras basearam-se no cotidiano clínico e de campo de estágio de graduação em fonoaudiologia. Acredita-se que, a partir dessa descrição, seja possível refletir criticamente as práticas em fonoaudiologia neonatal e buscar evidências que subsidiem cientificamente a indicação e o uso da técnica "sonda-dedo" como método alternativo de alimentação e/ou tecnologia de intervenção nos casos de disfunção oral.

\section{RESULTADOS}

As experiências foram agrupadas nos quadros a seguir, de acordo com os serviços.

\section{DISCUSSÃO}

Percebe-se que o objetivo e a indicação da técnica "sonda-dedo" para o recém nascido a termo são semelhantes nos três serviços. O que difere são os materiais e as técnicas utilizadas. Com relação aos diferentes tipos de luva empregada, sugere-se repensar o uso da luva de procedimento de látex. A literatura refere que o látex pode ser causador de alergias $^{5}$ e o talco interfere no gosto do estimulo, oferecendo paladar aversivo para o bebê. Quanto ao uso da seringa ou copo como utensílio de oferecimento do leite materno, verifica-se que nos três serviços o principio das técnicas é o mesmo, ou seja, oferecer o leite somente no momento em que o RN apresentar adequação do padrão de sucção, o que coincide com a literatura ${ }^{6-8}$.

Já a técnica "sonda-dedo" para o pré-termo é bastante distinta nos três serviços, especialmente quanto ao objetivo e indicação. Considera-se que, diferentemente do recém nascido a termo, o prétermo não apresenta disfunção oral uma vez que, a priori, a função de sucção ainda é imatura devido à própria condição do bebê e será desenvolvida a partir da maturidade e experiência, processos nos quais o fonoaudiólogo apresenta um importante papel. Em Ribeirão Preto-SP não se utiliza essa técnica em prematuros. Em Irati-PR, é indicada somente nos casos de treino de sucção e em Joinville-SC, além do treino, utiliza-se a "sonda-dedo" como forma de complementação após alimentação no seio materno. A literatura aponta a "sonda-dedo" tanto como treino de sucção quanto complemento quando a mãe está amamentando, porém ausente no momento da alimentação ${ }^{7}$. Destaca-se a necessidade de estudos longitudinais afinal desconhecem-se as consequencias do uso da "sondadedo" como complemento exclusivo, ou seja, utilizado em todos os horários de alimentação sem que o recém nascido tenha sido amamentado, para a prevalência do aleitamento materno e desenvolvimento sensório motor oral do prematuro.

Inexistem trabalhos científicos que utilizaram a técnica "sonda-dedo", tanto em recém nascido a termo com o em pré-termo. Alguns autores descrevem "sonda-dedo" como uma técnica que auxilia a alimentação, pois o bebê suga somente o que é capaz ${ }^{6,7}$, sendo ainda um método alternativo de alimentação ao copinho e à mamadeira quando a mãe amamenta mas está ausente ${ }^{7,9}$. A grande diferença da descrição da literatura com as dos serviços apresentados refere-se ao uso do dedo mínimo enluvado. Os autores descrevem o uso do dedo indicador ao invés do mínimo ${ }^{6-8}$. Justifica-se o uso do dedo mínimo pelo tamanho desse último ser semelhante ao mamilo materno, assim, prefere-se seu uso por essa correspondência, além do dedo mínimo ser amplamente utilizado para avaliação da sucção não nutritiva e para estimulá-la. Estudos futuros devem ser realizados para responder a essa lacuna.

Finalmente, questiona-se se a técnica "sondadedo" deve ser indicada somente nos casos em que seja caracterizada disfunção oral em recém nascido a termo. Sugere-se que, no pré-termo, a finalidade deve ser de treino de sucção quando a mãe está ausente ou como complemento com a mãe presente, desde que o prematuro já tenha sido aleitado. Sempre que possível, deve ser dada preferência para técnicas de complementação que envolvem diretamente o seio materno ${ }^{3}$. Acreditase que a técnica "sonda-dedo" não deva servir de complemento exclusivo do aleitamento materno e que sua indicação seja realizada com critérios claros e objetivos. A literatura já disponibiliza outros métodos alternativos para a transição da alimentação gástrica para a via oral sem considerar a técnica "sonda-dedo" como uma delas ${ }^{10}$. Considerase indevido seu uso indiscriminado, sem a técnica adequada e por profissionais sem conhecimento específico das funções orais em neonatos. 


\begin{tabular}{|c|c|c|c|c|}
\hline \multicolumn{2}{|c|}{$\begin{array}{c}\text { Hospitais } \\
\text { Indicações/técnica }\end{array}$} & \multirow{2}{*}{\begin{tabular}{l}
\multicolumn{1}{c}{$\begin{array}{c}\text { Santa Casa de Irati } \\
\text { Irati-PR }\end{array}$} \\
Adequar padrão de sucção nutritiva \\
visando aleitamento materno
\end{tabular}} & \multirow{2}{*}{\begin{tabular}{l}
\multicolumn{1}{c}{$\begin{array}{c}\text { Hospital UNIMED } \\
\text { Joinvile-SC }\end{array}$} \\
Adequar padrão de suçãa nutritiva \\
visando aleitamento materno.
\end{tabular}} & \multirow{2}{*}{$\begin{array}{c}\text { HCFMRP } \\
\text { Ribeirão Preto-SP } \\
\text { Adequar padrão de sucção nutritiva } \\
\text { visando aleitamento materno. }\end{array}$} \\
\hline \multirow[b]{4}{*}{$\begin{array}{l}\text { RN } \\
\text { Termo }\end{array}$} & Objetivo & & & \\
\hline & Indicação & $\begin{array}{l}\text { Indicação para RN com disfunção } \\
\text { oral }^{*}\end{array}$ & $\begin{array}{l}\text { Indicação para RN com disfunção } \\
\text { oral }^{*}\end{array}$ & $\begin{array}{l}\text { Indicação para RN com disfunção } \\
\text { oral }^{\star}\end{array}$ \\
\hline & Materiais & $\begin{array}{l}\text { Sonda gástrica } n^{\circ} 4 \text {, luva de plástico } \\
\text { descartável estéril, esparadrapo e } \\
\text { seringa }\end{array}$ & $\begin{array}{l}\text { Sonda gástrica } \mathrm{n}^{\circ} 4 \text { ou } \mathrm{n}^{\circ} \mathrm{6} \text {, luva de } \\
\text { procedimento de látex, } \\
\text { esparadrapo tipo micropore e } \\
\text { seringa }\end{array}$ & $\begin{array}{l}\begin{array}{l}\text { Sonda gástrica } \\
\text { procedimento luva de } \\
\text { esparadrapo e copo }\end{array} \\
\text { le látex, }\end{array}$ \\
\hline & Procedimento & $\begin{array}{l}\text { A ponta da sonda cortada é fixada } \\
\text { com esparadrapo no dedo mínimo } \\
\text { envulado com fixação na lateral } \\
\text { interna. A outra extremidade da } \\
\text { sonda é conectada a seringa com } \\
\text { êmbolo, com leite cru ordenhado da } \\
\text { mãe. É realizado treino de sucção, } \\
\text { com } 5 \text { estímulos e uma pausa, com } \\
\text { intervenções que dependem do tipo } \\
\text { da disfunção oral para adequação } \\
\text { da função da sucção, com dedo } \\
\text { virado para baixo. O leite é } \\
\text { empurrado conforme ocorre } \\
\text { adequação do padrão de sucção } \\
\text { pelo bebê, momento em que a } \\
\text { polpa do dedo mínimo é voltada } \\
\text { para o palato duro. Após o uso do } \\
\text { "sonda-dedo", o bebê é } \\
\text { posicionado em seio materno. }\end{array}$ & $\begin{array}{l}\text { A ponta da sonda cortada é fixada } \\
\text { com micropore no dedo mínimo } \\
\text { envulado com fixação na lateral } \\
\text { interna. A outra extremidade da } \\
\text { sonda é conectada a seringa com } \\
\text { êmbolo, com leite cru ordenhado da } \\
\text { mãe. É realizado treino de sucção, } \\
\text { com } 5 \text { estímulos e uma pausa, com } \\
\text { intervenções que dependem do tipo } \\
\text { da disfunção oral para adequação } \\
\text { da função da sucção, com dedo } \\
\text { virado para baixo. o leite é } \\
\text { empurrado conforme ocorre } \\
\text { adequação do padrão de sucção } \\
\text { pelo bebê. Após o uso do "sonda- } \\
\text { dedo", o bebê é posicionado em } \\
\text { seio materno. }\end{array}$ & $\begin{array}{l}\text { A ponta da sonda cortada é fixada } \\
\text { com esparadrapo no dedo mínimo } \\
\text { envulado com fixação na lateral } \\
\text { externa. A outra extremidade da } \\
\text { sonda é conectada a um copo, com } \\
\text { leite cru ordenhado da mãe. O } \\
\text { copo é mantido abaixo da altura da } \\
\text { boca do RN até adequação do } \\
\text { padrão de sucção pelo bebê. } \\
\text { Quando o padrão de sucção é } \\
\text { adequado, posiciona-se o copo na } \\
\text { altura da boca do bebê ou um } \\
\text { pouco mais baixo, para que não } \\
\text { haja gavagem, fazendo com q o } \\
\text { bebê sugue para obter o leite. É } \\
\text { realizado treino de sucção, com } 5 \\
\text { estímulos e uma pausa, com } \\
\text { intervenções que dependem do tipo } \\
\text { da disfunção oral para adequação } \\
\text { da função da sução, com dedo } \\
\text { virado para baixo e após a } \\
\text { adequação do padrão a polpa do } \\
\text { dedo mínimo é voltada para o } \\
\text { palato duro. Após o uso do "sonda- } \\
\text { dedo", o bebê é posicionado em } \\
\text { seio materno. }\end{array}$ \\
\hline \multirow{4}{*}{$\begin{array}{l}\text { RN } \\
\text { Pré- } \\
\text { termo }\end{array}$} & Objetivo & $\begin{array}{l}\text { Adequar padrão de suç̧ão nutritiva } \\
\text { visando aleitamento materno }\end{array}$ & $\begin{array}{l}\text { Adequar padrão de sucção nutritiva } \\
\text { visando aleitamento materno }\end{array}$ & \\
\hline & Indicação & $\begin{array}{l}\text { Indicação para treino de sucção de } \\
\text { prematuros que estejam em } \\
\text { transição da alimentação gástrica } \\
\text { para via oral na ausência da mãe }\end{array}$ & $\begin{array}{l}\text { Indicação para treino de sucção de } \\
\text { prematuros e/ou como } \\
\text { complemento de via oral em RNs } \\
\text { que estejam em transição da } \\
\text { alimentação gástrica para via oral } \\
\text { na presença ou na ausência da } \\
\text { mãe }\end{array}$ & $\begin{array}{l}\text { Não tem sido utilizada esta técnica } \\
\text { no momento }\end{array}$ \\
\hline & Materiais & $\begin{array}{l}\text { Sonda gástrica no } 4 \text {, luva de plástico } \\
\text { descartável estéril, esparadrapo e } \\
\text { seringa }\end{array}$ & $\begin{array}{l}\text { Sonda gástrica } \mathrm{n}^{\circ} 4 \text { ou } \mathrm{n}^{\circ} \mathrm{6} \text {, luva de } \\
\text { procedimento le látex, } \\
\text { esparadrapo tipo micropore e } \\
\text { seringa. }\end{array}$ & \\
\hline & Procedimento & $\begin{array}{l}\text { A ponta da sonda cortada é fixada } \\
\text { com esparadrapo no dedo mínimo } \\
\text { envulado com fixação na lateral } \\
\text { interna. A outra extremidade da } \\
\text { sonda é conectada a seringa com } \\
\text { êmbolo, com leite cru ordenhado da } \\
\text { mãe. É realizado treino de sucção, } \\
\text { com } 5 \text { estímulos e uma pausa, com } \\
\text { intervenções que dependem do tipo } \\
\text { da disfunção oral para adequação } \\
\text { da função da sucção, com dedo } \\
\text { virado para baixo. O leite é } \\
\text { empurrado conforme ocorre } \\
\text { adequação do padrão de sucção } \\
\text { pelo bebê, momento em que a } \\
\text { polpa do dedo mínimo é voltada } \\
\text { para o palato duro. Após o uso da } \\
\text { "sonda-dedo", o bebê é } \\
\text { posicionado em seio materno. }\end{array}$ & $\begin{array}{l}\text { A ponta da sonda cortada é fixada } \\
\text { com esparadrapo no dedo mínimo } \\
\text { envulado com fixação na lateral } \\
\text { interna. A outra extremidade da } \\
\text { sonda é conectada a seringa com } \\
\text { êmbolo, com leite cru ordenhado da } \\
\text { mãe. É realizado treino de sucção, } \\
\text { com } 5 \text { estímulos e uma pausa, com } \\
\text { intervenções que dependem do tipo } \\
\text { da disfunção oral para adequação } \\
\text { da função da sucção, com dedo } \\
\text { virado para baixo. O leite é } \\
\text { empurrado conforme ocorre } \\
\text { adequação do padrão de sucção } \\
\text { pelo bebê. Na presença materna } \\
\text { utilizado após o oferecimento de } \\
\text { seio materno como forma de } \\
\text { complemento via oral. }\end{array}$ & \\
\hline
\end{tabular}

* Por disfunção oral entendem-se as alterações nos padrões de postura de lábios e língua, nos reflexos de procura, sucção e mordida, movimento e canolamento de língua, movimentação de mandíbula, força de sucção, ritmo de sucções por pausa e alterações na sucção ao seio materno, em lactentes saudáveis e que não apresentam intercorrências que justifiquem alterações na sucção ao seio materno².

Figura 1 - Objetivo, indicação, materiais e procedimentos da técnica "sonda-dedo" para recémnascidos a termo e pré-termo 


\begin{abstract}
The World Health Organization recommends breastfeeding exclusively to all newborns until the sixth month and on a complementary basis, until the second year of life. Thus, some techniques are performed in order to facilitate the breastfeeding, including the use of a cup and recently using the "probe-finger" technique. This practice is very controversial and there are few studies addressing the description of the technique, and indications and usage. This study aims at reporting the clinical experience in order to show and use the "finger-probe" technique. The "probe-finger" technique is offering milk, preferably human milk, using a gastric tube connected to a syringe plunger and fixed on a gloved finger with a tape. The probe is positioned in the oral cavity of the newborn and should serve as a technical aid for sucking adequacy. Thus, it is suggested that his statement should be done just in cases where an oral dysfunction is characterized, either in newborns at term or preterm. Given the specific evaluation performed by the speech therapist, indicating the "probe-finger" technique in order to adjust the changes obtained in the evaluation of non-nutritive sucking or breastfeeding. It is believed that the "probe-finger" technique is recommended as a supplement to breastfeeding, and should be further investigated in order to clarify the impact of the "probe-finger" technique on the prevalence of breast-feeding and oral motor development of born infants.
\end{abstract}

KEYWORDS: Newborn; Feeding; Breastfeeding

\section{REFERÊNCIAS}

1. Nascimento MBR, Issler H. Breastfeeding: making the difference in the development, health and nutrition of term and preterm newborns. Rev Hosp Clín Fac Med S Paulo. 2003; 58(1):49-60.

2. Sanches MTC. Manejo clínico das disfunções orais na amamentação. J Pediatr. 2004; 80(5 Suppl):S155-62.

3. Aquino RR, Osório MM. Relactation, translactation and breast-orogastric tube as transition methods in feeding preterm babies. J Hum Lact. 2009; 25(4): 420-6.

4. Evangelista D, Oliveira A. Transição alimentar em recém-nascidos com displasia broncopulmonar. Rev CEFAC. 2009; 11(1):102-9.

5. Mathias LAS, Botelho MPF, Botelho II; Oliveira LM, Yamamura SJB, Bonfá RLG et al. Prevalência de sinais/sintomas sugestivos de sensibilização ao látex em profissionais de saúde. Rev Bras Anestesiol. 2006; 56(2):137-46.

6. Rios IJA. Fonoaudiologia hospitalar. São José dos Campos: Pulso, 2003.

7. Rios IJA, Oliveira MBP, Farias PT, Barcellos SF, Tini V. Amamentando o prematuro. In: Hitos SF, Periotto MC. Amamentação: atuação fonoaudiológica.Uma abordagem prática e atual. Rio de Janeiro: Revinter, 2009.

8. Lang S. Aleitamento do Lactente. São Paulo: Santos, 1999.

9. Almeida $H$. Situações especiais do lactente. In: Carvalho MR, Tamez RN. Amamentação: bases científicas. Rio de Janeiro: Guanabara Koogan, 2005.

10. Aquino RR, Osório MM. Alimentação do recém-nascido pré-termo: métodos alternativos de transição da gavagem para o peito materno. Rev Bras Saúde Matern Infant. 2008; 8(1):11-6.

http://dx.doi.org/10.1590/S1516-18462011005000021

RECEBIDO EM: 01/09/2010

ACEITO EM: 26/10/2010

Endereço para correspondência:

Cristina Ide Fujinaga

Rua Nossa Senhora de Fátima, 256 - apto 2

Irati-PR

CEP: $84500-000$

E-mail: cifujinaga@gmail.com 